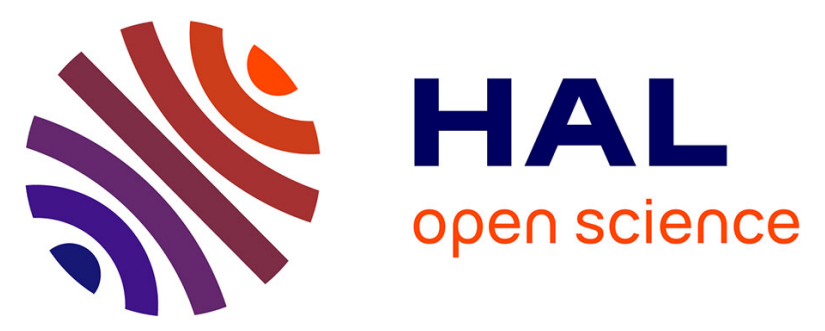

\title{
Isolation and Phospholipid Enrichment of Muscle Mitochondria and Mitoplasts
}

Alexandre Prola, Aymeline Vandestienne, Nabil Baroudi, Frédéric Joubert, Laurent Tiret, Fanny Pilot-Storck

\section{To cite this version:}

Alexandre Prola, Aymeline Vandestienne, Nabil Baroudi, Frédéric Joubert, Laurent Tiret, et al.. Isolation and Phospholipid Enrichment of Muscle Mitochondria and Mitoplasts. Bio-protocol , 2021, 11, 10.21769/bioprotoc.4201 . hal-03432287

\section{HAL Id: hal-03432287 https://hal.science/hal-03432287}

Submitted on 17 Nov 2021

HAL is a multi-disciplinary open access archive for the deposit and dissemination of scientific research documents, whether they are published or not. The documents may come from teaching and research institutions in France or abroad, or from public or private research centers.
L'archive ouverte pluridisciplinaire HAL, est destinée au dépôt et à la diffusion de documents scientifiques de niveau recherche, publiés ou non, émanant des établissements d'enseignement et de recherche français ou étrangers, des laboratoires publics ou privés. 


\title{
Isolation and Phospholipid Enrichment of Muscle Mitochondria and Mitoplasts
}

Alexandre Prola ${ }^{1,2,3, \$, *}$, Aymeline Vandestienne ${ }^{1,2,3}$, Nabil Baroudi ${ }^{1,2,3,4}$,

Frederic Joubert ${ }^{4}$, Laurent Tiret ${ }^{1,2,3}$ and Fanny Pilot-Storck ${ }^{1,2,3}$

\begin{abstract}
${ }^{1}$ Univ Paris-Est Créteil, INSERM, IMRB, Team Relaix, F-94010 Créteil, France; 'École nationale vétérinaire d'Alfort, IMRB, F-94700 Maisons-Alfort, France; ${ }^{3} \mathrm{EFS}$, IMRB, F-94010 Créteil, France; ${ }^{4}$ Laboratoire Jean Perrin, CNRS, Sorbonne Université, UMR 8237, F-75005 Paris, France; ${ }^{\$}$ Present address: Department of Cell Physiology and Metabolism, Faculty of Medicine, University of Geneva, 1 rue Michel-Servet, $\mathrm{CH}-1211,1202$ Geneva, Switzerland
\end{abstract}

*For correspondence: Alexandre.Prola@unige.ch

[Abstract] The efficient ATP production in mitochondria relies on the highly specific organization of its double membrane. Notably, the inner mitochondrial membrane (IMM) displays a massive surface extension through its folding into cristae, along which concentrate respiratory complexes and oligomers of the ATP synthase. Evidence has accumulated to highlight the importance of a specific phospholipid composition of the IMM to support mitochondrial oxidative phosphorylation. Contribution of specific phospholipids to mitochondrial ATP production is classically studied by modulating the activity of enzymes involved in their synthesis, but the interconnection of phospholipid synthesis pathways often impedes the determination of the precise role of each phospholipid. Here, we describe a protocol to specifically enrich mitochondrial membranes with cardiolipin or phosphatidylcholine, as well as a fluorescence-based method to quantify phospholipid enrichment. This method, based on the fusion of lipid vesicles with isolated mitochondria, may further allow a precise evaluation of phospholipid contribution to mitochondrial functions.

Keywords: Cardiolipin, Phosphatidylcholine, Vesicles, Acridine Orange 10-Nonyl Bromide, NAO, TopFluor CL, Mitotracker

[Background] Membranes in living cells are more than just barriers; they are also the sites of many important biological processes. Phospholipids are key membrane components, and by controlling membrane fluidity, permeability, rigidity, and morphology, they can modulate important functions. In eukaryote cells, mitochondria are at the crossroad of many cellular processes, including ATP production and apoptosis, and are altered in different diseases. Two membranes with different levels of permeability and unique phospholipid composition constitute their envelope. In particular, the inner mitochondrial membrane (IMM) is characterized by the presence of long invaginations called "cristae" that are enriched in cardiolipin (CL), a specific mitochondrial phospholipid. $C L$ is established as a crucial actor of mitochondrial architecture and ATP production (Paradies et al., 2014; Ikon and Ryan 2017a; Schlame et al., 2017; Pennington et al., 2019), and alteration of CL synthesis or content may result in the development of the Barth syndrome, a rare, life-threatening cardiomyopathy (Barth et al., 1983; Ikon et al., 2017b), or skeletal muscle weakness (Prola et al., 2021). More recently, a tight regulation of other 
phospholipids such as phosphatidic acid or phosphatidylethanolamine has been shown to be essential for mitochondrial function (Adachi et al., 2016; Heden et al., 2019). However, the roles of phospholipids in mitochondrial function have mostly been identified through the mutation of genes involved in their synthesis, and this indirect approach might lead to biases. For example, knockout of the tafazzin gene to study the role of $\mathrm{CL}$ is not only associated with a drop in mature $\mathrm{CL}$ content, but also with a strong enrichment of unmatured CL (monolyso- and dilyso-CL) that impairs mitochondrial function. Thus, complementary methods to study the role of phospholipids in mitochondrial function are needed. Previous publications used different methods to enrich mitochondria with $\mathrm{CL}$, phosphatidylserine, or phosphatidylglycerol, but the validation of the enrichment and a complete description of the protocols used are lacking (Bobyleva et al., 1997; Piccotti et al., 2002). Here, we describe a new method that we used to demonstrate the direct, key role of $\mathrm{CL}$ in the control of mitochondrial coupling in skeletal muscle (Prola et al., 2021). This method relies on the fusion of lipid vesicles with isolated mitochondria to enrich mitochondrial membranes with a single phospholipid. Below, we will discuss details of the protocol set up in our laboratory and also present our post-experimental data analysis and quality control workflow.

\section{Materials and Reagents}

1. Cell strainer $(100 \mu \mathrm{m}$, Greiner Bio-One $)$

2. $50 \mathrm{ml}$ centrifuge tube (Falcon)

3. Strengthened centrifuge $15 \mathrm{ml}$ glass tube (Kimble Chase, catalog number: 45500)

4. Glass Pasteur pipette (Dutscher, catalog number: 065421)

5. $1.5 \mathrm{ml}$ and $2 \mathrm{ml}$ Microtubes (Eppendorf)

6. Pipette tips (Star Lab)

7. 96-well plate (black, $\mu$ clear flat bottom; Greiner, catalog number: 655096)

8. Acridine Orange 10-Nonyl Bromide (Sigma, catalog number: A7847)

9. Adenosine 5'-diphosphate monopotassium salt dihydrate (Sigma, catalog number: A5285)

10. Bicinchoninic acid assay (Pierce, Invitrogen, catalog number: 23225)

11. Bovine serum albumin (fatty acid free; Sigma, catalog number: A7030)

12. Cardiolipin sodium salt from bovine Heart (chloroform solution; Avanti Polar Lipids, catalog number: $840012 \mathrm{C}$ )

13. Chloroform (Sigma, catalog number: 288306)

14. Digitonin (Sigma, catalog number: D5628)

15. Dimethyl sulfoxide (Sigma, catalog number: D8418)

16. Ethylene-bis(oxyethylenenitrilo)tetraacetic acid (EGTA) (Sigma, catalog number: 03777)

17. Ethylenediaminetetraacetic acid tetrasodium salt dihydrate (EDTA) (Sigma, catalog number: E6511)

18. Formaldehyde solution $36 \%$ (Sigma, catalog number: 47608)

19. Glutamate (Sigma, catalog number: G1501)

20. HEPES (Sigma, catalog number: H3375) 
21. Magnesium Chloride ( $\mathrm{MgCl}_{2} 1 \mathrm{M}$ solution; Sigma, catalog number: 63069$)$

22. Malate (Sigma, catalog number: M6413)

23. Mannitol (Sigma, catalog number: M8429)

24. Methanol (Sigma, catalog number: 34860 )

25. MitoTracker ${ }^{\mathrm{TM}}$ Red CMXRos (Invitrogen, catalog number: M7512)

26. PBS (Sigma, catalog number: P4417)

27. L-a-phosphatidylcholine (95\%) (Egg, Chicken, chloroform solution) (Sigma, catalog number: 131601C)

28. Potassium Phosphate monobasic $\left(\mathrm{KH}_{2} \mathrm{PO}_{4}\right.$; Sigma, catalog number: P5655)

29. Pyruvate (Sigma, catalog number: P2256)

30. Sucrose (Sigma, catalog number: S0389)

31. Texas Red ${ }^{T M}$ 1,2-Dihexadecanoyl-sn-Glycero-3-Phosphoethanolamine, Triethylammonium Salt (Thermofischer, catalog number: T1395MP)

32. TopFluor ${ }^{\circledR}$ Cardiolipin (Avanti Polar Lipids, catalog number: 810286)

33. Tris-HCl (Sigma, catalog number: T5941)

34. Trypsin EDTA (10× $0.5 \% / 0.2 \%$ in DPBS (PAA Laboratories, catalog number: L11-003)

35. Mouse anti-COXIV antibody (Abcam, catalog number: ab14744)

36. Rabbit anti- $\beta$-tubulin antibody (Cell Signaling, catalog number: 2128)

37. Rabbit anti-Calnexin antibody (Sigma, catalog number: C4731)

38. Mouse anti-elF2 $\alpha$ antibody (Cell Signaling, catalog number: 2103)

39. Rabbit anti-Insulin Receptor $\beta$ antibody (Cell signaling, catalog number: 3025)

40. Rabbit anti-MFF antibody (Abcam, catalog number: ab129075)

41. Rabbit anti-TBP antibody (Cell Signaling, catalog number: 8515)

42. Rabbit anti-VDAC antibody (Custom made, a kind gift from Dr. C. Lemaire, Inserm U1180)

43. Mitochondria Homogenization Buffer (MHB) (see Recipes)

44. Mitochondria Isolation Buffer (MIB) (see Recipes)

45. ADP solution (see Recipes)

46. Fusion buffer (see Recipes)

47. 10× BSA solution (see Recipes)

48. Digitonin solution (see Recipes)

49. Mitoplast Preparation Buffer (MPB) (see Recipes)

50. Hypotonic Mitoplast Preparation Buffer (HMPB) (see Recipes)

51. Mitotracker Red $1 \mathrm{mM}$ stock solution (see Recipes)

52. Formaldehyde $2 \%$ (see Recipes)

53. Nonyl-acridine orange $35 \mathrm{mM}$ stock solution (see Recipes) 


\section{Equipment}

1. Centrifuge (Eppendorf, model: $5810 \mathrm{R}$ with rotor FA-45-6-30)

2. Dounce, $2 \mathrm{ml}$ (Kimble, Type A, catalog number: 885300-0002)

3. Hamilton syringe $500 \mu \mathrm{l}$ (ThermoFischer, catalog number: 10570042)

4. Nitrogen or argon gas bottle, or medical gas installation with pressure regulator

5. Non- $\mathrm{CO}_{2}$ incubator (Memmert, catalog number: D06057, Model 100)

6. MACSMIX Tube rotator (Miltenyi, catalog number: 130-090-753)

7. Spectrofluorimeter (TECAN, model: Infinite M200)

8. Sonicator bath (Branson, catalog number: 3510)

9. Zeiss LSM800 confocal (Zeiss, model: LSM800)

10. Water bath

\section{Software}

1. Prism 8 (GraphPad Software, www.graphpad.com)

2. Software Magellan (TECAN)

3. Zen (Zeiss)

\section{Procedure}

A. Isolation of mitochondria

The objective is to isolate mitochondria from the cells or tissues of choice. The protocol presented here was optimized for the isolation of mitochondria from mouse skeletal muscle (Prola et al., 2021), with a protocol adapted from Frezza et al. (2007). It may need to be adapted to the specificity of the cells or tissue of choice.

Notes:

a. It is crucial to obtain pure and functional mitochondria prior to the phospholipid enrichment experiment. To preserve mitochondria properties throughout the procedure, it is important to i) work with freshly isolated mitochondria, ii) reduce at its minimum the time between the different steps of the procedure, and iii) keep mitochondria on ice or at $4^{\circ} \mathrm{C}$ all throughout the procedure.

b. Precool Dounce in an ice-bath 5 min before starting the procedure and equilibrate the centrifuge at $4^{\circ} \mathrm{C}$.

1. Kill the mouse by cervical dislocation. Using a scalpel, rapidly remove the skeletal muscles of interest and immerse them in a small beaker containing $5 \mathrm{ml}$ of ice-cold PBS supplemented with 10 mM EDTA.

Note: Local and national regulations on animal care and handling vary. Ensure that you hold the appropriate authorization to perform animal experiments. 
2. In the same beaker, mince the muscles into small pieces using scissors and remove visible fat, ligaments, and connective tissue.

3. Wash the minced muscles twice or thrice with $1 \mathrm{ml}$ of ice-cold PBS supplemented with $10 \mathrm{mM}$ EDTA.

4. Transfer the minced muscles using a large opening pipette tip in ice-cold PBS supplemented with $10 \mathrm{mM}$ EDTA and $0.05 \%$ trypsin-0.02\% EDTA (approximately $1 \mathrm{ml}$ of solution in a $2 \mathrm{ml}$ tube per $100 \mathrm{mg}$ of muscle). Mince with scissors in very small pieces (need 2/3 min for each tube), and incubate for $30 \mathrm{~min}$ at $4^{\circ} \mathrm{C}$.

5. Centrifuge at $200 \times g$ for $5 \mathrm{~min}$ at $4^{\circ} \mathrm{C}$ and discard the supernatant.

6. Resuspend the pellet in ice-cold Mitochondria Homogenization Buffer (MHB; see Recipes). The optimal ratio between tissue and isolation buffer ranges between 1:10 and 1:30 (w:v) (the following protocol corresponds to $2.5 \mathrm{ml}$ for $100 \mathrm{mg}$ of muscle).

7. Homogenize muscles using a Dounce (100 up and down strokes with pestle A). Homogenization, as well as the following steps, must be performed at $4^{\circ} \mathrm{C}$.

8. Pass the homogenate through a $100 \mu \mathrm{m}$ cell strainer into a $50 \mathrm{ml}$ polypropylene Falcon tube.

9. Centrifuge at $700 \times g$ for $10 \mathrm{~min}$ at $4^{\circ} \mathrm{C}$.

10. Carefully transfer the supernatant (by reverting the tube) into a glass centrifuge tube and centrifuge at $8,000 \times g$ for $10 \mathrm{~min}$ at $4^{\circ} \mathrm{C}$.

Note: Up to $200 \mu$ l of the homogenate obtained in Step A9 may be used for bicinchoninic acid quantitation and western blot analysis. To ensure the purity of mitochondria preparation, avoid transferring any visible material from the pellet. Glass tubes are preferred because (i) they are better thermic insulators to preserve mitochondria and (ii) they cause reduced binding of mitochondria compared to plastic, which avoids material loss, allowing the preparation of a smaller and more concentrated pellet compared to plastic tubes.

11. Discard the supernatant and resuspend the pellet in $5 \mathrm{ml}$ of ice-cold Mitochondria Isolation Buffer (MIB).

12. Centrifuge at $8,000 \times g$ for $10 \mathrm{~min}$ at $4^{\circ} \mathrm{C}$.

13. Discard the supernatant and resuspend the pellet containing mitochondria in the small amount of buffer that remains after discarding the supernatant (around $100 \mu \mathrm{l}$, avoid adding more MIB). Mitochondria are now ready to be used.

14. Use $1 \mu \mathrm{l}$ of the mitochondrial suspension to quantify mitochondrial protein content using bicinchoninic acid (BCA) assay (He, 2011).

Notes:

a. Hereafter, mitochondria quantity will refer to the mitochondrial protein content as quantified here.

b. Functionality of mitochondria can be checked by measuring mitochondrial coupling as previously described (Mourier et al., 2014). Purity of mitochondria can be checked by western blot, as shown in Figure 1. One hundred milligrams of muscle typically yields 500 $1,000 \mu \mathrm{g}$ of mitochondria. Following steps for fusion with phospholipid vesicles must be 
done on freshly isolated mitochondria (the same day). For other applications, such as western blot, mitochondria could be aliquoted and snap frozen in liquid nitrogen.

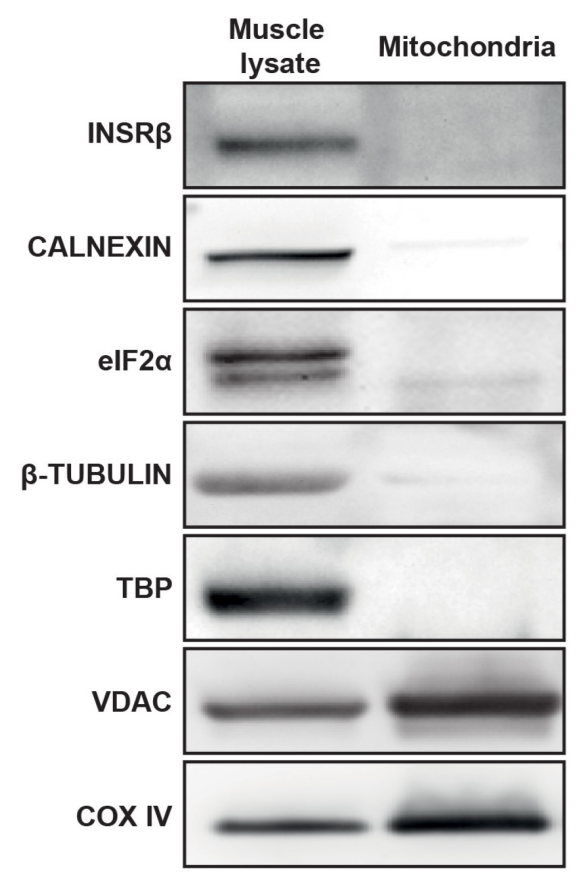

Figure 1. Representative western blot with crude muscle lysate or purified mitochondria. INSR $\beta$ : Insulin receptor $\beta$ (plasma membrane), CALNEXIN (endoplasmic reticulum), elF2 $\alpha$ (cytoplasm), $\beta$-TUBULIN (cytoskeleton), TBP (nucleus), VDAC (outer mitochondrial membrane), and COX IV (inner mitochondrial membrane). These blots confirmed the enrichment in mitochondria as well as the absence of remnants from other subcellular compartments after the isolation procedure.

B. Production of pure phospholipid vesicles (PV)

Note: Manipulate lipids using stainless steel, glass, or Teflon. Do not use plastic tubes or pipette tips. See Figure 2 for pictures taken during different steps of the protocol.
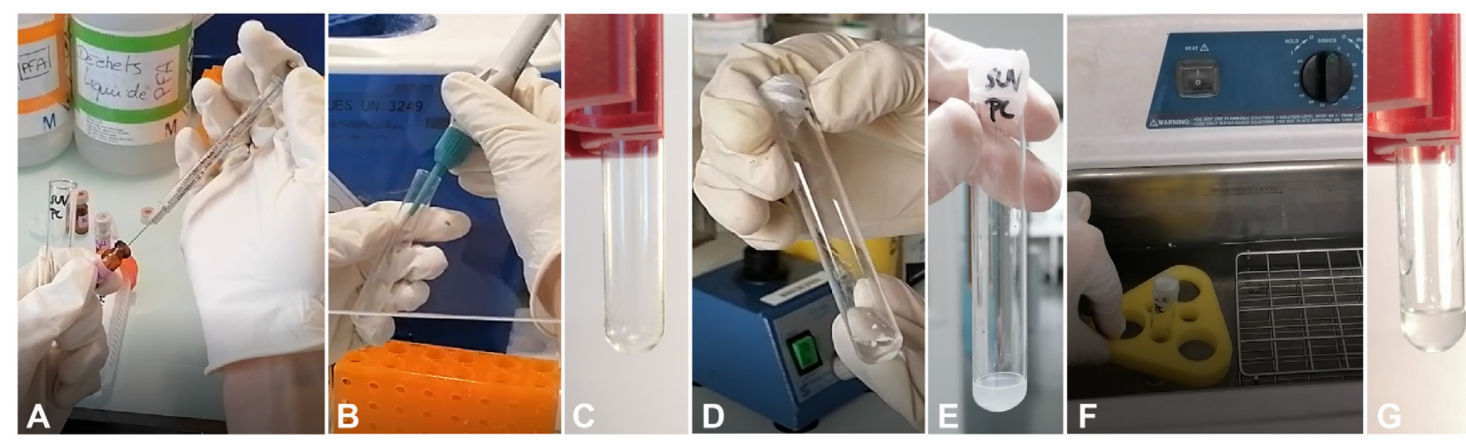

Figure 2. Workflow for the production of phospholipid vesicles. A. Put phospholipids in a glass tube using a Hamilton syringe. B. Evaporate chloroform using argon or nitrogen gas. C. Evaporated 
phospholipids form a thin film on the tube. D. Add $1 \mathrm{ml}$ of MIB to the tube and incubate for one hour. E. Vortex for $30 \mathrm{~s}$, the solution should then appear cloudy. F. Sonicate for $25 \mathrm{~min}$ in a water bath sonicator. G. After sonication, the solution should be clear. Repeat sonication if it is not the case.

1. Using a Hamilton syringe, put $2 \mathrm{mg}$ of phospholipids $(200 \mu \mathrm{l}$ from $10 \mathrm{mg} / \mathrm{ml}$ chloroform stock solution) into a glass tube and evaporate the chloroform using nitrogen or argon gas propelled at 0.2 bar. Rotate the tube during evaporation to form a thin lipid film on the tube (see Video 1). Note: For the production of fluorescent PV, put $0.2 \mathrm{mg}$ of fluorescent phospholipids and $1.8 \mathrm{mg}$ of non-fluorescent phospholipids. Protect from light throughout the procedure. Tubes may be placed for one hour in a vacuum pump to evaporate the chloroform.

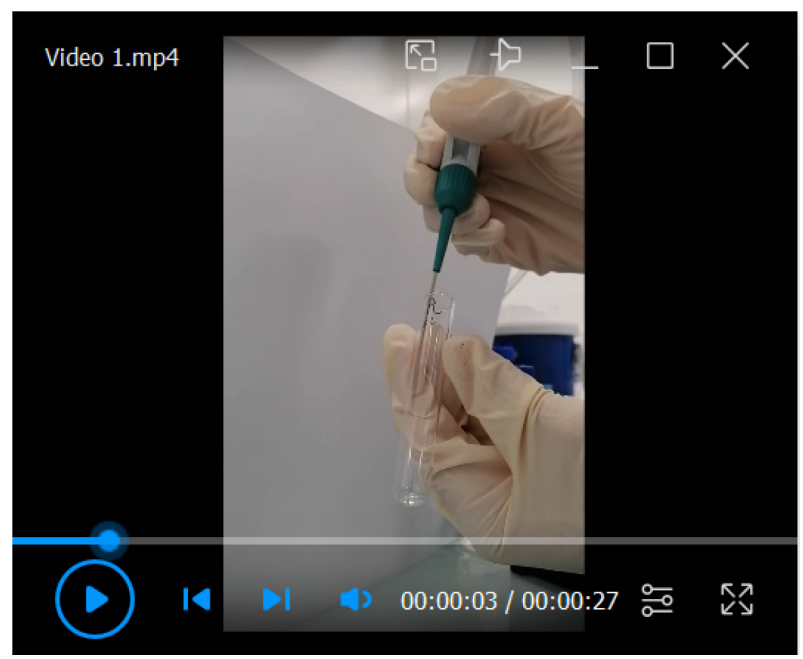

Video 1. Evaporation of chloroform using argon gas

2. Add $1 \mathrm{ml}$ of MIB (pre-equilibrated at room temperature) in the tube, incubate for one hour at room temperature, and then vortex during $30 \mathrm{~s}$. The solution should appear cloudy. Final PV concentration are around $1.38 \mathrm{mM}$ for $\mathrm{CL}(\mathrm{MW}=1449.9 \mathrm{~g} / \mathrm{mol})$ and $2.60 \mathrm{mM}(\mathrm{MW}=770.1$ $\mathrm{g} / \mathrm{mol}$ ) for PC.

3. Sonicate the phospholipid solution for $25 \mathrm{~min}$ in a water bath sonicator $(40 \mathrm{kHz})$ filled with ice. Repeat this step until obtaining a clear solution.

Note: Tubes are held on a plastic rack placed in the water bath sonicator. A probe sonicator may also be used.

4. Use immediately or store the solution at $4^{\circ} \mathrm{C}$ for one week. Re-sonicate prior to each experiment under the same conditions.

Note: Once produced, PV can be manipulated using classical plastic tips.

C. Fusion of PV with isolated mitochondria

1. Put $500 \mu \mathrm{g}$ of freshly isolated mitochondria (according to the BCA assay) into a $2 \mathrm{ml}$ microtube, add $2.5 \mathrm{mM}$ ADP ( $5 \mu \mathrm{l}$ from the $500 \mathrm{mM}$ ADP solution; see Recipes), $15 \mathrm{nmol}$ of PV (10.9 $\mu \mathrm{l}$ of 
$1.38 \mathrm{mM}$ CL stock solution or $5.8 \mu \mathrm{l}$ of $2.60 \mathrm{mM} \mathrm{PC}$ stock solution), and complete to $1 \mathrm{ml}$ with Fusion buffer pre-heated at $30^{\circ} \mathrm{C}$.

Note: Add reagents in the following order: mitochondria, ADP solution, fusion buffer, and PV.

2. Incubate for $20 \mathrm{~min}$ at $30^{\circ} \mathrm{C}$ under constant stirring agitation (12 rotations per minute).

Note: Incubation time and temperature were optimized here for $C L$ and $P C$ incorporation into muscle mitochondria. They may need to be optimized for other phospholipid species or sources of mitochondria. Increasing temperature and incubation duration increases phospholipid enrichment. Over-enrichment should be avoided as it hampers mitochondrial function.

3. Add $1 \mathrm{ml}$ of ice-cold MIB to stop fusion.

Note: Cooling the buffer increases membrane rigidity, which in combination with the dilution of $A D P, P V$, and mitochondria results in inhibition of fusion.

4. Centrifuge at $10,000 \times g$ for $10 \mathrm{~min}$ at $4^{\circ} \mathrm{C}$ to pellet mitochondria.

Note: Over-enriched mitochondria may not pellet and may remain in the supernatant.

5. Discard all the supernatant and resuspend the pellet in $100 \mu \mathrm{l}$ of ice-cold MIB and layer on an ice-cold sucrose gradient ( $1 \mathrm{ml}$ of $0.6 \mathrm{M}$ sucrose in a $2 \mathrm{ml}$ microtube) to remove unfused PV and overfused mitochondria.

6. Centrifuge at $10,000 \times g$ for $10 \mathrm{~min}$ at $4^{\circ} \mathrm{C}$ to pellet mitochondria.

7. Discard all the supernatant and wash the pellet with $1 \mathrm{ml}$ of ice-cold MIB.

8. Centrifuge at $10,000 \times g$ for $10 \mathrm{~min}$ at $4^{\circ} \mathrm{C}$ to pellet mitochondria.

9. Discard all the supernatant and resuspend enriched mitochondria with the buffer of your choice. Enriched mitochondria are now ready to be used.

Notes:

a. Enriched mitochondria are highly sensitive to mechanical stress, so pipet and manipulate them carefully (no vortex, no up and down, aspirate and eject softly with a $200 \mu$-pipette). Perform the experiment quickly after the enrichment.

b. Appropriate controls for these experiments could be (i) mitochondria submitted to the same protocol but in the presence of vehicle only (MIB) instead of PV or (ii) mitochondria fused with PV made of another control lipid.

D. Mitoplast preparation

To validate the enrichment of IMM with phospholipids, the outer mitochondrial membrane (OMM) can be stripped away by permeabilization combined with osmotic shock to produce purified objects called mitoplasts (IMM plus matrix), using the following procedure (adapted from Chazotte and Hackenbrock, 1988):

Note: Precool the Dounce in an ice-bath 5 min before starting the procedure.

1. Prepare the OMM permeabilization solution: $100 \mu \mathrm{l}$ of 10× BSA solution (see Recipes), mitochondria suspension (from A13), digitonin $(0.12 \mu \mathrm{g}$ of digitonin per $\mu \mathrm{g}$ of mitochondrial proteins, e.g., for $100 \mu \mathrm{g}$ of mitochondria, add $12 \mu \mathrm{l}$ of digitonin solution at $1 \mathrm{mg} / \mathrm{ml}$; see Recipes) and complete to $1 \mathrm{ml}$ with Mitoplast Preparation Buffer (MPB; see Recipes). 
Note: Add reagents in the following order: MPB, mitochondria, 10× BSA, and then digitonin. One $\mathrm{ml}$ is sufficient for up to $500 \mu \mathrm{g}$ of mitochondria; for a higher amount, the volume should be increased.

2. Incubate for 15 min at $4^{\circ} \mathrm{C}$ under constant stirring agitation (12 rotations per minute).

3. Centrifuge at $8,000 \times g$ for $10 \mathrm{~min}$ at $4^{\circ} \mathrm{C}$.

4. Discard the supernatant and resuspend the pellet in $1 \mathrm{ml}$ of ice-cold Hypotonic Mitoplast Preparation Buffer (HMPB; see Recipes) and incubate for $15 \mathrm{~min}$ at $4^{\circ} \mathrm{C}$ with shaking.

5. Homogenize mitochondria using a Dounce (100 up and down strokes with pestle A).

6. Centrifuge at $8,000 \times g$ for $10 \mathrm{~min}$ at $4^{\circ} \mathrm{C}$.

7. Discard the supernatant and resuspend the pellet in $1 \mathrm{ml}$ of ice-cold HMPB and centrifuge at $8,000 \times g$ for $10 \min$ at $4^{\circ} \mathrm{C}$.

8. Discard the supernatant and resuspend the pellet with the buffer of your choice. Mitoplasts are now ready to use.

Note: When placed in hypotonic buffer, mitoplasts are devoid of cristae and form large vesicles around $1 \mu \mathrm{m}$ in diameter. Efficiency of the purification can be verified by microscopic observation (Figure 3A). Mitoplasts can be stained by resuspending the pellet with a buffer containing Mitotracker (dilute the $1 \mathrm{mM}$ stock solution to $100 \mathrm{nM}$ in the buffer of your choice). After $10 \mathrm{~min}$ of incubation at room temperature, centrifuge at $8,000 \times \mathrm{g}$ for $10 \mathrm{~min}$, discard the supernatant, and resuspend the pellet in the buffer of your choice (e.g., HMPB) to distinguish them from pure lipid vesicles (Figure 3B). Absence of contamination with proteins from the OMM can be checked by western blot (Figure 3C).

A

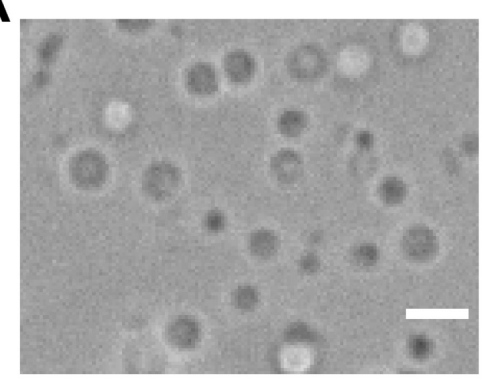

B

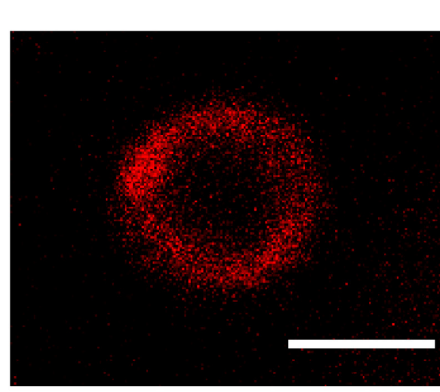

C

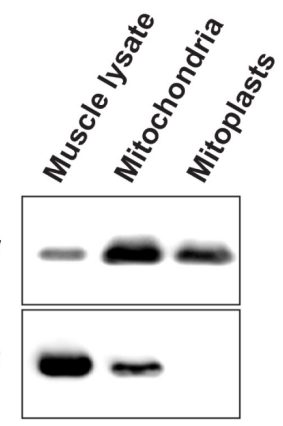

Figure 3. Validation of mitoplast preparation. A. Representative mitoplast shape and size in HMPB buffer. Scale bar, $2 \mu \mathrm{m}$. B. Mitoplasts stained with MitoTracker Red. Scale bar, $1 \mu \mathrm{m}$. C. MFF (outer mitochondrial membrane) and COX IV (inner mitochondrial membrane) protein content in total muscle lysate, purified mitochondria, and mitoplasts. These blots confirmed the enriched proportion of mitochondrial proteins in purified mitochondria as well as the absence of remnants from the outer mitochondrial membrane in mitoplasts. 
E. Validation of phospholipid enrichment

The use of fluorescent lipids allows validating the enrichment of mitochondria with phospholipids. For $\mathrm{CL}$, the enrichment can also be validated using the Acridine Orange 10-Nonyl Bromide (NAO) probe, which binds to CL (Garcia Fernandez et al., 2004).

1. Fluorescent lipids

a. Use the protocol described in Procedure $\mathrm{C}$ to fuse mitochondria with PV containing fluorescent lipids (see the note in B1).

b. Mitochondria enrichment with phospholipids can then be checked by measuring fluorescence with a spectrofluorimeter or through the observation of fluorescence by microscopy according to fluorescence properties of the lipid used (Figure 4).
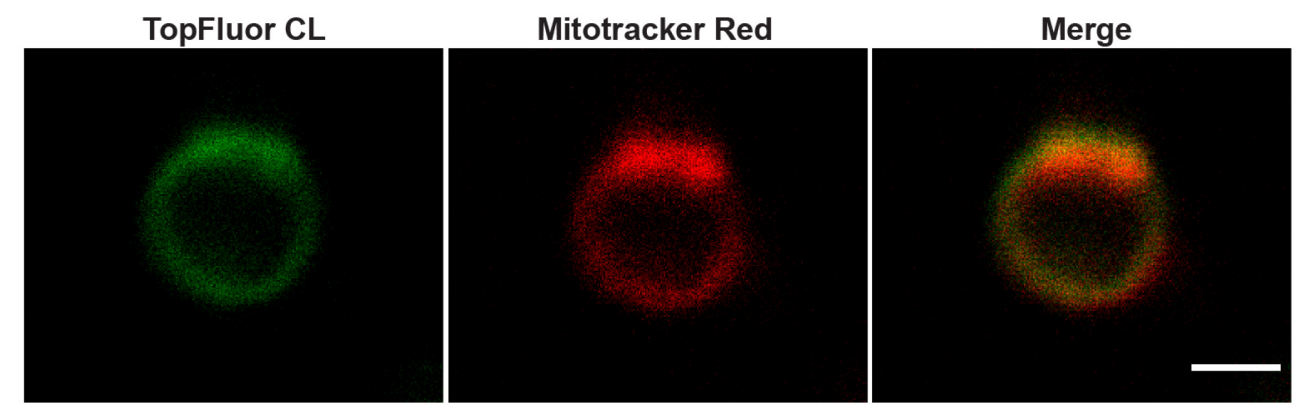

Figure 4. Cardiolipin enrichment and MitoTracker Red staining. Representative images of mitoplasts made from mitochondria after fusion with TopFluor-Cardiolipin (CL) vesicles and stained with Mitotracker Red. Scale bar: $1 \mu \mathrm{m}$.

c. If incorporation in the IMM is expected, mitoplasts can be prepared from enriched mitochondria (see Procedure D) and checked as in Figure 3.

2. NAO quantification

Note: Experimental controls with mitochondria not stained with NAO must be included for quantification (see Data analysis).

a. After enrichment with $\mathrm{CL}$ as described in Procedure $\mathrm{C}$, fix isolated mitochondria or mitoplasts (100 $\mathrm{\mu g}$ of proteins) with formaldehyde $2 \%$ (see Recipes) for $15 \mathrm{~min}$, at $4^{\circ} \mathrm{C}$.

Note: Fixation before NAO staining is recommended to dissipate mitochondrial membrane potential that interferes with NAO fluorescence.

b. Centrifuge at $10,000 \times g$ for $10 \mathrm{~min}$ at $4^{\circ} \mathrm{C}$.

c. Discard the supernatant and resuspend the pellet with $1 \mathrm{ml}$ of ice-cold PBS.

d. Centrifuge at $10,000 \times g$ for $10 \mathrm{~min}$ at $4^{\circ} \mathrm{C}$.

e. Discard the supernatant and resuspend the pellet in $100 \mu \mathrm{l}$ of PBS supplemented with $35 \mu \mathrm{M}$ of NAO (from a $35 \mathrm{mM}$ stock solution in DMSO; see Recipes).

f. Incubate for $10 \mathrm{~min}$ at room temperature. 
g. Centrifuge at $10,000 \times g$ for $10 \mathrm{~min}$ at $4^{\circ} \mathrm{C}$.

h. Discard the supernatant and resuspend the pellet with $1 \mathrm{ml}$ of ice-cold PBS.

i. Centrifuge at $10,000 \times g$ for $10 \mathrm{~min}$ at $4^{\circ} \mathrm{C}$.

j. Discard the supernatant and resuspend the pellet in $100 \mu \mathrm{l}$ of PBS and transfer in 96-well plate (black, $\mu$ clear flat bottom).

k. Measure fluorescence ( $\lambda$ excitation: $495 \mathrm{~nm}, \lambda$ emission: $620 \mathrm{~nm}$ ) with a spectrofluorimeter (Figure 5).
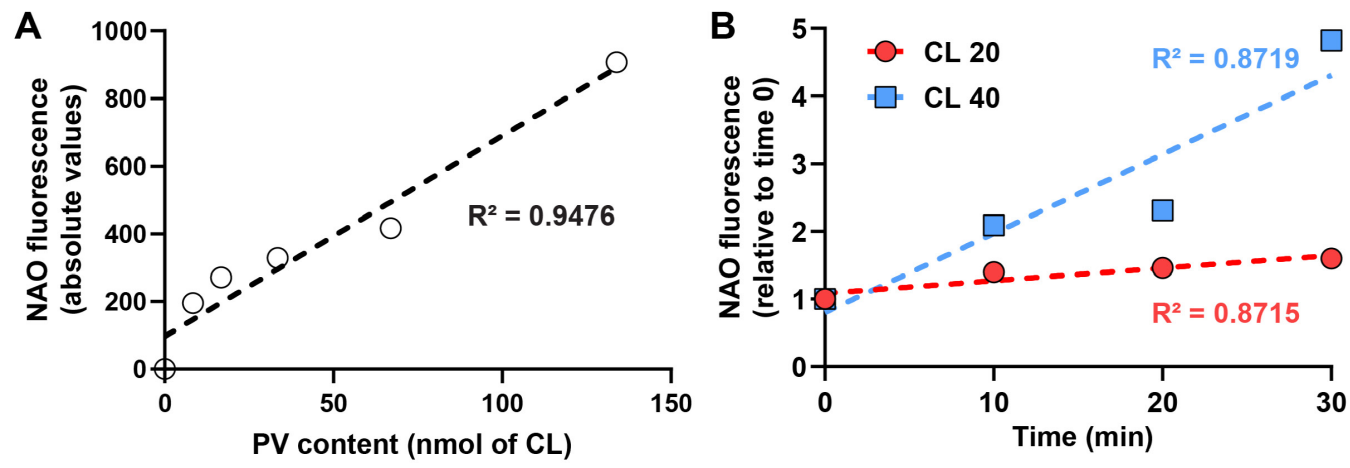

Figure 5. Cardiolipin enrichment and NAO quantification. A. NAO fluorescence in the presence of varying amounts of $P V$ made of $C L$. Linear regression is shown in dotted line with respective $\mathrm{R}^{2}$ fitting. B. NAO fluorescence after fusion of $500 \mu \mathrm{g}$ of mitochondria with 20 (red) or 40 (blue) $\mathrm{nmol}$ of $\mathrm{CL}$ vesicles during 0 (control), 10,20 , and $30 \mathrm{~min}$ at $30^{\circ} \mathrm{C}$. Results are shown relative to the control set to 1.0. Linear regression is shown in dotted line with respective $R^{2}$ fitting.

\section{Data analysis}

For fluorescence analysis on a spectrophotometer (fluorescent lipids or NAO experiments described in procedure $\mathrm{E}$ ), the values obtained were corrected from blank (mitochondria with no fluorescent lipids or not stained with NAO) and normalized on mitochondrial protein content. Values are then expressed as relative to control set to 1.0 .

\section{$\underline{\text { Notes }}$}

1. This protocol has been optimized for the enrichment of mitochondrial membranes with $C L$ and PC. Some adjustments may be required for the enrichment with other phospholipids and validated using fluorescent lipids.

2. While the ATP/O ratio is not impacted by the enrichment with $\mathrm{CL}$, the absolute rate of respiration and ATP production are both decreased, as previously reported (Prola et al., 2021). This may be due to respiratory chain complex dilution within the membrane (Schneider et al., 1980) or to 
an impairment in lipid arrangement following phospholipid enrichment. PC enrichment impairs both the absolute rate of respiration and ATP/O ratio.

3. This multi-step procedure induces a loss of material, and thus, a large quantity of mitochondria is mandatory at the start (depending on the application, use at least $300 \mu \mathrm{g}$ of mitochondria).

\section{Recipes}

1. Mitochondria Homogenization Buffer (MHB)

$67 \mathrm{mM}$ sucrose

$50 \mathrm{mM} \mathrm{KCl}$

10 mM EDTA

$0.2 \% \mathrm{BSA}$

$50 \mathrm{mM}$ Tris- $\mathrm{HCl}$

$\mathrm{pH} 7.40$ (buffered with $1 \mathrm{M} \mathrm{KOH}$ solution)

Store at $-20^{\circ} \mathrm{C}$ for several months without BSA.

Ready to use solution with BSA can be stored for one week at $4^{\circ} \mathrm{C}$.

2. Mitochondria Isolation Buffer (MIB)

$250 \mathrm{mM}$ sucrose

3 mM EGTA

$10 \mathrm{mM}$ Tris- $\mathrm{HCl}$

$\mathrm{pH} 7.40$ (buffered with $1 \mathrm{M} \mathrm{KOH}$ solution)

Store at $-20^{\circ} \mathrm{C}$ for several months or one week at $4^{\circ} \mathrm{C}$.

Note: For Recipes 1 and 2, see Frezza et al. (2007) for more detailed instructions.

3. ADP solution

$500 \mathrm{mM}$ ADP

$150 \mathrm{mM} \mathrm{MgCl} 2$

Aliquots can be stored at $-20^{\circ} \mathrm{C}$.

4. Fusion buffer

$220 \mathrm{mM}$ mannitol

$70 \mathrm{mM}$ sucrose

2 mM HEPES

$10 \mathrm{mM} \mathrm{KH}_{2} \mathrm{PO}_{4}$

$5 \mathrm{mM} \mathrm{MgCl} 2$

1 mM EGTA

$10 \mathrm{mM}$ glutamate

$2 \mathrm{mM}$ malate

$10 \mathrm{mM}$ pyruvate

pH 6.50 (buffered with $1 \mathrm{M} \mathrm{KOH}$ solution)

Store at $-20^{\circ} \mathrm{C}$ for several months or one week at $4^{\circ} \mathrm{C}$. 
5. 10× BSA solution

Dilute $5 \mathrm{mg}$ of fatty acid free BSA in $1 \mathrm{ml}$ of MPB. Use the same day.

6. Digitonin solution

Dilute $1 \mathrm{mg}$ of digitonin in $1 \mathrm{ml}$ of MPB, heat at $95^{\circ} \mathrm{C}$ for $5 \mathrm{~min}$, and cool on ice before use.

Use the same day.

7. Mitoplast Preparation Buffer (MPB)

$70 \mathrm{mM}$ sucrose

$220 \mathrm{mM}$ mannitol

2 mM HEPES

$\mathrm{pH} 7.40$ (buffered with $1 \mathrm{M} \mathrm{KOH}$ solution)

Store at $-20^{\circ} \mathrm{C}$ for several months or one week at $4^{\circ} \mathrm{C}$.

8. Hypotonic Mitoplast Preparation Buffer (HMPB)

Dilute MPB 7.5 times in deionized $\mathrm{H}_{2} \mathrm{O}$ (e.g., $6 \mathrm{ml}$ of MPB and $39 \mathrm{ml}$ of deionized $\mathrm{H}_{2} \mathrm{O}$ for $45 \mathrm{ml}$ of HMPB). Use the same day.

9. Mitotracker Red $1 \mathrm{mM}$ stock solution

Add $94 \mu \mathrm{l}$ of DMSO to $50 \mu \mathrm{g}$ vial. Aliquots and store at $-20^{\circ} \mathrm{C}$.

10. Formaldehyde $2 \%$

Dilute formaldehyde stock solution in PBS.

11. Nonyl-acridine orange $35 \mathrm{mM}$ stock solution

Dilute $10 \mathrm{mg}$ of NAO in $605 \mu \mathrm{l}$ of DMSO. Aliquots can be stored at $-20^{\circ} \mathrm{C}$.

\section{Acknowledgments}

This work was primarily supported by the "Association Française contre les Myopathies" (AFM 16143, Translamuscle I \#19507 and Translamuscle II \#22946).

This method was originally used in Prola et al. (2021) for Science Advances, DOI: 10.1126/sciadv.abd6322.

\section{Competing interests}

The authors declare that they have no conflicts of interest or competing interests.

\section{$\underline{\text { References }}$}

1. Adachi, Y., Itoh, K., Yamada, T., Cerveny, K. L., Suzuki, T. L., Macdonald, P., Frohman, M. A., Ramachandran, R., lijima, M. and Sesaki, H. (2016). Coincident Phosphatidic Acid Interaction Restrains Drp1 in Mitochondrial Division. Mol Cell 63(6): 1034-1043.

2. Barth, P. G., Scholte, H. R., Berden, J. A., Van der Klei-Van Moorsel, J. M., Luyt-Houwen, I. E., Van 't Veer-Korthof, E. T., Van der Harten, J. J. and Sobotka-Plojhar, M. A. (1983). An X-linked 
Please cite this article as: Prola, A. et al. (2021). Isolation and Phospholipid Enrichment of Muscle Mitochondria and Mitoplasts. Bio-protocol 11(20): e4201. DOI: 10.21769/BioProtoc.4201.

mitochondrial disease affecting cardiac muscle, skeletal muscle and neutrophil leucocytes. $J$ Neurol Sci 62(1-3): 327-355

3. Bobyleva, V., Bellei, M., Pazienza, T. L. and Muscatello, U. (1997). Effect of cardiolipin on functional properties of isolated rat liver mitochondria. Biochem Mol Biol Int 41(3): 469-480.

4. Chazotte, B. and Hackenbrock, C. R. (1988). The multicollisional, obstructed, long-range diffusional nature of mitochondrial electron transport. J Biol Chem 263(28): 14359-14367.

5. Frezza, C., Cipolat, S. and Scorrano, L. (2007). Organelle isolation: functional mitochondria from mouse liver, muscle and cultured fibroblasts. Nat Protoc 2(2): 287-295.

6. Garcia Fernandez, M. I., Ceccarelli, D. and Muscatello, U. (2004). Use of the fluorescent dye 10-N-nonyl acridine orange in quantitative and location assays of cardiolipin: a study on different experimental models. Anal Biochem 328(2):174-180.

7. He, F. (2011). BCA (Bicinchoninic Acid) Protein Assay. Bio-101: e44.

8. Heden, T. D., Johnson, J. M., Ferrara, P. J., Eshima, H., Verkerke, A. R. P., Wentzler, E. J., Siripoksup, P., Narowski, T. M., Coleman, C. B., Lin, C. T., et al. (2019). Mitochondrial PE potentiates respiratory enzymes to amplify skeletal muscle aerobic capacity. Sci Adv 5(9): eaax8352.

9. Ikon, N. and Ryan, R. O. (2017a). Cardiolipin and mitochondrial cristae organization. Biochim Biophys Acta Biomembr 1859(6): 1156-1163.

10. Ikon, N. and Ryan, R. O. (2017b). Barth Syndrome: Connecting Cardiolipin to Cardiomyopathy. Lipids 52(2): 99-108.

11. Mourier, A., Ruzzenente, B., Brandt, T., Kuhlbrandt, W. and Larsson, N. G. (2014). Loss of LRPPRC causes ATP synthase deficiency. Hum Mol Genet 23(10): 2580-2592.

12. Paradies, G., Paradies, V., De Benedictis, V., Ruggiero, F. M. and Petrosillo, G. (2014). Functional role of cardiolipin in mitochondrial bioenergetics. Biochim Biophys Acta 1837(4): 408417.

13. Pennington, E. R., Funai, K., Brown, D. A. and Shaikh, S. R. (2019). The role of cardiolipin concentration and acyl chain composition on mitochondrial inner membrane molecular organization and function. Biochim Biophys Acta Mol Cell Biol Lipids 1864(7): 1039-1052.

14. Piccotti, L., Marchetti, C., Migliorati, G., Roberti, R. and Corazzi, L. (2002). Exogenous phospholipids specifically affect transmembrane potential of brain mitochondria and cytochrome C release. J Biol Chem 277(14): 12075-12081.

15. Prola, A., Blondelle, J., Vandestienne, A., Piquereau, J., Denis, R. G. P., Guyot, S., Chauvin, H., Mourier, A., Maurer, M., Henry, C., et al. (2021). Cardiolipin content controls mitochondrial coupling and energetic efficiency in muscle. Sci Adv 7(1): eabd6322.

16. Schlame, M., Xu, Y. and Ren, M. (2017). The Basis for Acyl Specificity in the Tafazzin Reaction. J Biol Chem 292(13): 5499-5506.

17. Schneider, H., Lemasters, J. J., Hochli, M. and Hackenbrock, C. R. (1980). Liposomemitochondrial inner membrane fusion. Lateral diffusion of integral electron transfer components. J Biol Chem 255(8): 3748-3756. 
